\title{
Changes in the expression of c-myc, RB and tyrosine- phosphorylated proteins during proliferation of NIH 3T3 cells induced by hyaluronic acid
}

\author{
Soon-Ok Moon, ${ }^{1,3} \mathrm{Ji}-\mathrm{Hy} u n$ Lee ${ }^{1}$ and \\ Tai-Jin Kim² \\ 1 Division of Life Science, The University of Suwon, Suwon 445-743, \\ Korea \\ 2 Department of Chemical engineering, The University of Suwon, \\ Suwon 445-743, Korea \\ 3 Corresponding author \\ Accepted 17 February 1998
}

Abbreviations: IL-1, interleukin-1; TNF- $\alpha$, tumor necrosis factor- $\alpha$; FAK, focal adhesion kinase; ATCC, American type culture collection; DMEM, Dulbesco's modified Eagle's medium; SRB, sulforhodamin B; $p R b$, RB product

\begin{abstract}
We have shown that hyaluronic acid stimulates the proliferation of quiescent NIH 3T3 cells. We have shown that treatment of $1 \mathrm{mg} / \mathrm{ml}$ hyaluronic acid results in increase of tyrosine phosphorylation of two proteins, MW $124 \mathrm{kDa}$ and $60 \mathrm{kDa}$ as detected by anti-tyrosine antibodies by Western blot analysis. Maximum phosphorylation occurred within $2 \mathrm{~h}$ after addition of $1 \mathrm{mg} / \mathrm{ml}$ hyaluronic acid. Stimulation of proliferation was also accompanied by increase in c-Myc protein, which was inhibited by amiloride, an inhibitor of $\mathrm{Na}^{+} / \mathrm{H}^{+}$antiporter and EGTA and increase in the steady state level of $\mathrm{pRb}$, the RB gene product. These results suggest that the intracellular signal transduction pathways that mediate the stimulatory effects of hyaluronic acid on cellular proliferation are similar to those of growth factors.
\end{abstract}

Keywords: proliferation, tyrosine phosphorylation, c-myc, pRb, hyaluronic acid

\section{Introduction}

Hyaluronic acid, an extracellular matrix glycosaminoglycan, is an linear polysaccharide containing glucuronic acid and $\mathrm{N}$-acetylglucosamine as a repeating unit. Hyaluronic acid provides stability and elasticity to the extracellular matrix by interaction with proteoglycans and other matrix components (Knudson and Knudson, 1993). Hyaluronic acid has been thought to be important not only as a structural role in extracellular matrix, but also as biological roles. The main biological function of hyaluronic acid is still unknown but recently several functions have been elucidated. Brecht et al. (1986) have suggested that hyaluronic acid is involved in the mitotic process. Hyaluronic acid also has been shown to promote cell motility in vitro and contribute to the motile responses of cells during wound repair, tumor invasion and tissue morphogenesis (Turley, 1984; Weigel et al., 1986; Toole et al., 1989). Hyaluronic acid has been previously been linked with both transformation and metastastic process (Turley, 1992). Hyaluronic acid has also been recognized in clinical medicine. Analysis of serum hyaluronic acid is promising in the diagnosis of liver disease and various inflammatory conditions. Interstitial edema caused by accumulation of hyaluronic acid may cause dysfunction in various organs (Laurent and Fraser, 1992). Also hyaluronic acid has been reported to regulate the expression of several cytokine genes. In bone marrow derived macrophages, soluble hyaluronic acid stimulated IL-1, TNF- $\alpha$, and insulin like growth factor-1 mRNA transcript expression (Hiro et al., 1986; Noble et al., 1993).

It has been proposed that hyaluronic acid mediates its biological function by interacting with hyaluronic acid binding proteins in the extracellular matrix and hyaluronic acid receptors on the cell surface (Aruffo et al., 1990; Harwick et al., 1992). Interactions between hyaluronic acid and the cell surface receptors generate a variety of biochemical signaling events including transient increase of tyrosine phosphorylation of several proteins leading to focal adhesion turnover (Hall et al., 1994) and selective expression of genes (Noble et al., 1993). Focal adhesions are sites of extracelluar matrix receptor-cytoskeletal interactions, where second messenger signaling commonly occurs in response to extracellular matrix and some growth factors. These structures are believed to be critical for the regulation of growth and cell motility (Burridge et al., 1992). Focal adhesion kinase (FAK), pp125 FAK a tyrosine kinase, recently localized in focal adhesions, has been implicated in several signaling pathways that involve extracellular matrix receptors as well as in transformation (Schaller et al., 1992; Schlaepfer et al., 1994). Relationship of FAK and ras signaling pathway is well studied in fibronectin and integrin interaction on NIH 3T3 cells. Fibronectin binding to integrins on NIH 3 T3 cells promotes C-src and FAK association and increase FAK tyrosine phosphorylation (Guan and Shalloway, 1992; Schaller et al., 1992) and FAK protein tyrosine kinase activity (Guan and Shalloway, 1992). Phosphorylation of FAK 
upon fibronectin stimulation creates an $\mathrm{SH}$-binding site for GRB2 which may link integrin engagement to the activation of Ras signal transduction pathway (Schlaepfer et al., 1994).

These results indicate that hyaluronic acid may regulate the cell proliferation through activation of FAK-Ras pathway. However, cell proliferation affected by hyaluronic acid is not established and mechanism by which this occurs are not fully understood. In this present study, we have attempted to elucidate the intracellular signal transduction pathways that mediate the growth stimulatory effects of hyaluronic acid. We have focused on the changes in the expression of c-myc and RB and tyrosine phosphorylation

\section{Materials and Methods}

\section{Cell culture}

NIH 3T3 cells were obtained from American Type Culture Collection (ATCC) and cultured in Dulbecco's modification of Eagle's minimal essential medium (DMEM) supplemented with $5 \%$ bovine calf serum (Gibco, Gaithersburg, USA), $50 \mu \mathrm{g} / \mathrm{ml}$ penicillin, and $50 \mathrm{unit} / \mathrm{ml}$ streptomycin in a humidified incubator containing of $5 \% \mathrm{CO}_{2}$ at $37^{\circ} \mathrm{C}$.

\section{Cell proliferation}

Quiescent cells were obtained by serum deprivation $(0.5 \%$ BCS) for two days. Cell proliferation was determined by using sulforhodamin B (SRB, Sigma, St. Louis, USA) assay. SRB assay was performed as described (Rubinstein et al., 1990). After quiescent NIH 3T3 cells were treated with hyaluronic acid (prepared from culture of Streptomyces equi: ATCC 9528 as described in Yoon et al., 1993) for one day, media was aspirated and $10 \%$ trichloroacetic acid was added. After $1 \mathrm{~h}$ incubation at $4^{\circ} \mathrm{C}$, plate was washed 5 times by using tap water and air dried. Cells were stained with $0.4 \%(\mathrm{w} / \mathrm{v}) \mathrm{SRB}$ for $30 \mathrm{~min}$ at room temperature and washed 5 times by using $1 \%$ acetic acid. Bound SRB was solubilized with $10 \mathrm{mM}$ Tris and absorbance was measured at $520 \mathrm{~nm}$.

\section{Western blot analysis}

After quiescent cells were treated with hyaluronic acid or hyaluronic acid plus amiloride (Sigma, St. Louis USA) or EGTA. NIH 3T3 cells were lysed directly in SDS loading buffer, heated to $100^{\circ} \mathrm{C}$ for $5 \mathrm{~min}$ and protein was quantitated by using Bio-Rad microassay kit (Bio-Rad, Hercules, USA). Same amount of protein was resolved by SDSPAGE. After electrophoresis, the separated polypeptides were electrophoretically transferred to nitrocellulose membrane (Schleicher \& Schull, Keene, USA) by using electrotransfer kit (Hoefer, San Francisco, USA). The membrane was immersed in blocking buffer $[0.2 \%(\mathrm{w} / \mathrm{v})$ I-block $^{\text {TM }}$, 1XPBS, 0.1\% (v/v) Tween-20] for $1 \mathrm{~h}$ at room temperature to block nonspecific binding and incubated for $1 \mathrm{~h}$ with each primary antibody. The antibodies were rabbit polyclonal $\mathrm{pRb}$ antibody (Ab-2, oncogene science, New York, USA), rabbit polyclonal anti-c-Myc antibody (UBI, New York, USA), and mouse monoclonal antiphosphotyrosine antibody (Transduction Laboratories, Lexington, USA). The membranes were washed in $0.1 \%(\mathrm{v} / \mathrm{v})$ Tween-20/PBS and incubated with biotinylated secondary antibody in blocking buffer for 1 $\mathrm{h}$ at room temperature. After washing, membranes were incubated in alkaline phosphatase conjugated streptavidin containing blocking buffer for $30 \mathrm{~min}$ at room temperature. Bands were visualized by incubating the membrane in substrate solution containing 5-bromo-4-chloro-3-indolyl phosphate and nitroblue tetrazolium.

\section{Results and Discussion}

\section{The effect of hyaluronic acid on the proliferation of NIH 3 T3 cells}

Recently, it has been known that hyaluronic acid and other glycosaminoglycans have effects on cell proliferation and transformation (Turley, 1992; Knudson and Knudson, 1993). Overexpression of one of isoforms of hyaluronic acid receptor CD44 increase primary and secondary tumor growth and also cells overexpressing RHAMM resemble ras-transformed fibroblasts (Hall et al., 1995). However, the molecular mechanisms underlying hyaluronic acid regulation of cell proliferation are unknown. For elucidation of the signal transduction pathway that is responsible for this process, first, we observed the effect of hyaluronic acid on NIH 3T3 cell proliferation. We treated various concentration of hyaluronic acid to quiescent NIH 3T3

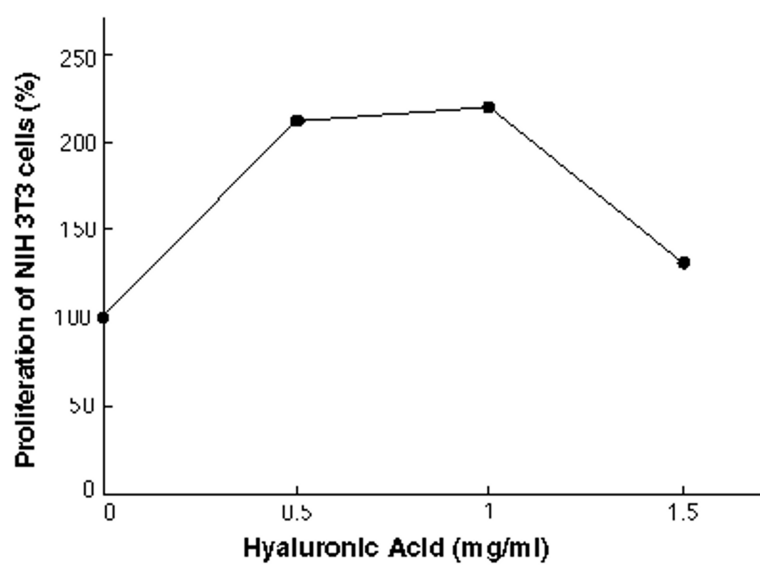

Figure 1. Effect of hyaluronic acid on the proliferation of $\mathrm{NIH} 3 \mathrm{~T} 3$ cells. After quiescent $\mathrm{NIH} 3 \mathrm{~T} 3$ cells were incubated with $0.5-1.5 \mathrm{mg} / \mathrm{ml}$ hyaluronic acid for $24 \mathrm{~h}$. SRB assay was performed. This is a representative plot of five similar experiments. Results are expressed as the percentage of control cells which are cultured in $0.5 \%$ serum media. 
cells for $24 \mathrm{~h}$ and SRB assay was performed. Hyaluronic acid stimulated proliferation of NIH 3 T3 cells 2.0 -fold and maximum effect was observed at $1 \mathrm{mg} / \mathrm{ml}$ hyaluronic acid (Figure 1).

\section{The effect of hyaluronic acid on the tyrosine phosphorylation}

One of the best known responses stimulated by hyaluronic acid is tyrosine phosphorylation of several proteins (Hall et al., 1994; Hall et al., 1995). To analyze the signaling through tyrosine phosphorylation in hyaluronic acid treated quiescent NIH 3T3 cells, we have studied phosphotyrosine containing proteins with anti-phosphotyrosine antibody (Figure 2). Hyaluronic acid stimulated the phosphorylation of $124 \mathrm{kDa}$ and $60 \mathrm{kDa}$ proteins. Molecular weights of these proteins were similar to those of FAK (125 kDa) and c-src (60 kDa) (Turley, 1989; Burridge et al., 1992). Tyrosine phosphorylation of these proteins have been implicated to be related in hyaluronic acid induced cell motility (Hall et al., 1994, 1995). Phospho-rylation increases within one hour after addition of $1 \mathrm{mg} / \mathrm{ml}$ hyaluronic acid and maximum effect was observed after two hours. In contrast to our result, Hall et al. (1994) reported that phosphorylation peaked within one minute of hyaluronic acid stimulation. They used much lower concentration $(10 \mathrm{ng} / \mathrm{ml})$ of hyaluronic acid than that we used. We also observed minor stimulation of phosphorylation within three minutes (data not shown). This different time dependent phosphorylation may be resulted from stimulation of different receptor according to different concentration of hyaluronic acid. Further investigation should be performed to identify these two proteins and to confirm that phosphorylation of these proteins are critical for proliferation of NIH 3T3 cells by using the inhibitor of

(A)

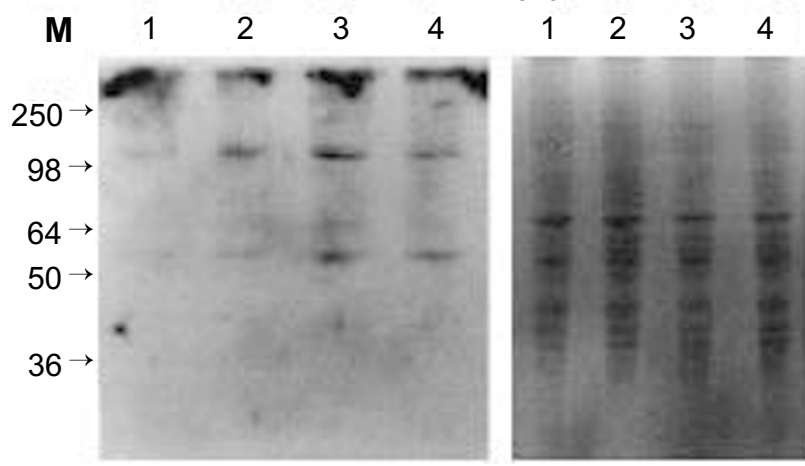

Figure 2. Effect of hyaluronic acid on tyrosine phosphorylation. Quiescent NIH 3 T3 cells were incubated with $1 \mathrm{mg} / \mathrm{ml}$ hyaluronic acid for $0 \mathrm{~h}$ (lane 1), $1 \mathrm{~h}$ (lane 2), $2 \mathrm{~h}$ (lane 3), or $3 \mathrm{~h}$ (lane 4 ) before cell lysis. $5 \mu \mathrm{g}$ of total protein was electrophoresed on SDS-PAGE gel and transferred to nitrocellulose membrane and detected by using anti-phosphotyrosine antibody (A). The equivalent gel was stained with Coomassie blue (B). tyrosine kinases.

\section{The effect of hyaluronic acid on c-Myc protein expression}

The expression of c-myc is closely associated with growth in various cell types. The expression of c-myc is induced transiently with maximal expression occurring two hours after serum stimulation at the level of mRNA (Moore et al. 1986). To investigate whether hyaluronic acid stimulates this important proto-oncogene as other mitogens, we treated quiescent NIH 3T3 cells with $1 \mathrm{mg} / \mathrm{ml}$ hyaluronic acid and Western blot analysis was performed. Figure 3 shows that hyaluronic acid causes increase of steady state level of c-Myc protein within one hour. Rapid increase of c-Myc protein by hyaluronic acid suggests that this is important signal of hyaluronic acid necessary for cells to proceed from $G_{0}$ to $G_{1}$.

\section{The effect of amiloride, an inhibitor of $\mathrm{Na}^{+} / \mathrm{H}^{+}$ antiporter and EGTA on the hyaluronic acid induced c-Myc protein expression}

To determine whether the intracellular signal transduction pathways, stimulated by hyaluronic acid are similar to those of growth factors, we investigated the significance of two important signaling molecules, $\mathrm{Na}^{+} / \mathrm{H}^{+}$and $\mathrm{Ca}^{2+}$ in hyaluronic acid induced c-Myc protein expression by using amiloride, an inhibitor of $\mathrm{Na}^{+} / \mathrm{H}^{+}$antiporter, and EGTA. One of the important early responses of cultured fibroblasts to growth factors is the activation of $\mathrm{Na}^{+} / \mathrm{H}^{+}$ antiporter which leads to a rise in cytoplasmic $\mathrm{pH}$. By using amiloride, the importance of $\mathrm{Na}^{+} / \mathrm{H}^{+}$antiporter in the induction of c-myc and also cell proliferation was found (Moon and Kim, 1993). Treatment of amiloride and EGTA with hyaluronic acid inhibited the increase of c-Myc protein induced by hyaluronic acid (Figure 4). We also found that amiloride and EGTA inhibited NIH 3T3 cell proliferation induced by hyaluronic acid (data not shown). This result supports that hyaluronic acid and growth factors stimulated the common signaling pathway to induce cell proliferation.

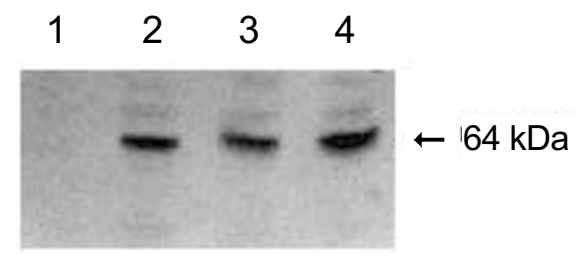

Figure 3. Effect of hyaluronic acid on the steady state level of c-Myc protein. Quiescent $\mathrm{NIH} 3 \mathrm{~T} 3$ cells were incubated with $1 \mathrm{mg} / \mathrm{ml}$ hyaluronic acid for $0 \mathrm{~h}$ (lane 1 ), $1 \mathrm{~h}$ (lane 2), $2 \mathrm{~h}$ (lane 3), or $3 \mathrm{~h}$ (lane 4 ) before cell lysis. Western blot analysis was performed with anti-c-Myc antibody as described in Material and Methods. The arrow indicates the 64 $\mathrm{kDa}$ c-Myc protein. 


\section{$\begin{array}{llllllll}1 & 2 & 3 & 4 & 5 & 6 & 7 & 8\end{array}$}

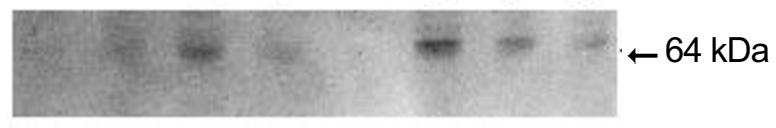

Figure 4. Effect of amiloride and EGTA on the hyaluronic acid induced c-Myc protein. Quiescent $\mathrm{NIH} 3 \mathrm{~T} 3$ cells were incubated with $1 \mathrm{mg} / \mathrm{ml}$ hyaluronic acid in the presence of $500 \mu \mathrm{M}$ amiloride (1-4) or $1 \mathrm{mM}$ EGTA (5-8) for $0 \mathrm{~h}$ (lane 1 and 5 ), $1 \mathrm{~h}$ (lane 2 and 6), $2 \mathrm{~h}$ (lane 3 and 7), or $3 \mathrm{~h}$ (lane 4 and 8 ) before cell lysis. Western blot analysis was performed with anti-c-Myc antibody as described in Material and Methods. The arrow indicates the $64 \mathrm{kDa}$ c-Myc protein.

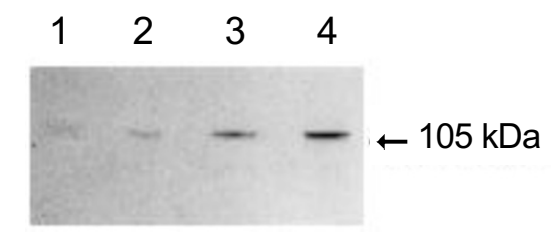

Figure 5. Effect of hyaluronic acid on the steady state level of $\mathrm{pRb}$. Quiescent NIH 3T3 cells were incubated with $1 \mathrm{mg} / \mathrm{ml}$ hyaluronic acid for $0 \mathrm{~h}$ (lane 1), $6 \mathrm{~h}$ (lane 2), $12 \mathrm{~h}$ (lane 3), or $24 \mathrm{~h}$ (lane 4 ) before cell lysis. Western blot analysis was performed with anti-pRb antibody as described in Material and Methods. The arrow indicates the 105 kDa pRb.

\section{The effect of hyaluronic acid on RB protein expression}

In addition to proto-oncogenes, the other important regulators of cell cycle are anti-oncogenes. RB is one of the well studied anti-oncogenes. pRb acts as a growth suppressor and prevent G1-S transition. The activity of $\mathrm{pRb}$ has been known to be regulated primarily by cell cycle dependent phosphorylation and only the hypophosphorylated form of $\mathrm{pRb}$ is able to interact with cellular proteins including E2F (DeCaprio et al., 1989). However, recently it has been shown that the expression of RB gene is subjected to cell cycle regulation and this process occurred through E2F binding site, located in RB promoter (Shan et al., 1994). To elucidate the relationship between hyaluronic acid and the $\mathrm{pRb}$, we investigated the effect of hyaluronic acid on the steady state level of $\mathrm{pRb}$ by Western blot analysis. Figure 5 shows that hyaluronic acid increases the amount of $p R b$. This result supports the previous evidences which showed that RB expression increases during cell cycle progression. It has been previously shown that $\mathrm{G}_{0}$-differentiated cells have less $\mathrm{pRb}$ than proliferating, immature cells (Yen et al., 1994) and $G_{1}$ cells have less $p R b$ than cell in other cell cycle phase (Yen and Chandler, 1992). Our result provides further evidence that the expression of the RB gene is subjected to cell cycle regulation. It will be interesting to study the mechanism by which hyaluronic acid increase the expression of RB.

Rapid responses of hyaluronic acid, such as stimulation of tyrosine phosphorylation and increase of c-Myc protein level which was dependent on $\mathrm{Na}^{+} / \mathrm{H}^{+}$and $\mathrm{Ca}^{2+}$, as shown in this paper, suggest that hyaluronic acid stimulates the cellular proliferation by stimulation of signal transduction pathway through interaction with specific receptor.

\section{Acknowledgement}

This study was supported by research fund from Ministry of Education, Korea (95-B-08)

\section{References}

Aruffo, A., Stamenkovic, I., Melnick, M., Underhill, C. B. and Seed, B. (1990) CD44 is the principal cell surface receptor for hyaluronate. Cell 61: 1303-1313

Brecht, M., Mayer, U., Schlosser, E. and Prehm, P. (1986) Increased hyaluronate synthesis is required for fibroblast detachment and mitosis. Biochem. J. 239: 445-450

Burridge, K., Turner, C. E. and Romer, L. H. (1992) Tyrosine phosphoryl-ation of paxillin and pp125 $5^{\mathrm{FAK}}$ accompanies cell adhesion to extracellular matrix: a role in cytoskeletal assembly. J. Cell Biol. 119: 893-903

Decaprio, J. A., Ludlow, J. W., Lynch, D., Furukawa, Y., Griffin, J., Piwnica, W. H., Huag, C. M. and Livingston, D. M. (1989) The product of the retinoblastoma susceptibility gene has properties of cell cycle regulatory element. Cell 58: 1085-1095

Guan, J.-L. and Shalloway, D. (1992) Regulation of focal adhesion-associated protein tyrosine kinase by both cellular adhesion and oncogenic transformation. Nature 358 : 690-692

Hardwick, C., Hoare, K., Owens, R., Hohn, H. P., Hook, M., Moore, D., Cripps, V. and Austen, L. (1992) Molecular cloning of a novel hyaluronan receptor that mediates tumor cell motility. J. Cell Biol. 117: 1343-1350

Hall, C. L., Wang, C., Lange, L. A. and Turley E. A. (1994) Hyaluronan and hyaluronan receptor RHAMM promote focal adhesion turnover and transient kinase activity. J. Cell Biol. 126: 575-588

Hall, C. L., Yang, B., Yang, X., Zhang, S., Turley, M., Samuel, S., Lange, L. A., Wang, C., Curpen, G. D., Savani, R. C., Greenberg, A. H. and Turley, E. A. (1995) Overexpression of hyaluronan receptor RHAMM is transforming and is also required for H-ras transformation. Cell 82: 19-28

Hiro, D., Ito, A., Matsuta, K. and Mori, Y. (1986) Hyaluronic acid is an endogenous inducer of interleukin-1 production by human monocytes and rabbit macrophages. Biochem. Biophys. Res. Comm. 140: 715-722

Knudson, C. B. and Knudson, W. (1993) Hyaluronan-binding proteins in development, tissue homeostasis, and disease. FASEB J. 7: 1233-1241

Laurent, T. C. and Fraser, R. E. (1992) Hyaluronan. FASEB J. 6: 2397-2404

Moon, S. O. and Kim, H. B. (1993) Importance of activation of $\mathrm{Na}^{+} / \mathrm{H}^{+}$antiporter in serum stimulated proliferation. Mol. Cells 3: 149-152

Moore, J. P., Todd, J. A., Hesketh, T. R. and Metcalf, J. C. (1986) c-fos and c-myc gene activation ionic signal and DNA synthesis in thymocytes. J. Biol. Chem. 261: 8158-8162 Noble, P. W., Lake, F. R., Henson, P. M. and Riches, W. H. (1993) Hyalu-ronate activation of $\mathrm{CD} 44$ induces insulin-like growth factor- 1 expression by a tumor necrosis factor- $\alpha$-dependent mechanism in murine macro-phages. J. Clin. Invest. 91: 2368-2377

Rubinstein, L. V., Shoemaker, R. H., Paul. K. D., Simon, R. M., Tosini, S., Skehan, P., Scudiero, D. A., Monk, A. and Boyd, M. R. (1990) Comparison of in vitro anticancer drug 
screening data generated with a tetrazolium assay versus a protein assay a diverse panel of human tumor cell lines. J. Natl. Cancer Inst. 82: 1113-1118

Shan, B., Chang, C.-Y., Jones, D. and Lee, W.-H. (1994) The transcription factor E2F-1 mediates the autoregulation of RB gene expression. Mol. Cell. Biol. 14: 299-309

Schaller, M. D., Borgman, C. A., Cobb, B. S. and Vine, R. R. (1992) pp125FAK, a structurally distinctive protein-tyrosine kinase associated with focal adhesions. Proc. Natl. Acad. Sci. USA 89: 5192-5196

Schlaepfer, M. D., Hanks, S. K., Hunt, J. and van der Geer, P. (1994) Integrin-mediated signal transduction linked to Ras pathway by GRB2 binding to focal adhesion kinase. Nature 372: 786-791

Toole, B. P., Munaim, S. F., Welles, S. and Knudson, C. B. (1989) Hyaluronate-cell interaction and growth factor regulation of hyaluronate synthesis during limb development Biology of Hyaluronan. Ciba Found. Symp. 143: 150-169

Turley, E. A. (1984) Proteoglycan and cell adhesion: their putative role during tumorigenesis. Cancer Metastasis Rev. 3: 325-339

Turley, E. A. (1989) Hyaluronic acid stimulates protein kinase activity in intact cells and in an isolated protein complex. J. Biol. Chem. 264: 8951-8955

Turley, E. A. (1992) Hyaluronan and cell locomotion. Cancer Metastasis Rev. 11: 21-30

Weigel, P. H., Fuller, G. M. and LeBoeuf (1986) A model for role of hyaluronic and fibrinogen in the early events during the inflammatory response and wound healing. $J$. Theor. Biol. 119: 219-234
Yen, A. and Chandler, S. (1992) Inducers of leukemic cell differentiation cause down regulation of RB gene expression. Proc. Soc. Exp. Biol. and Med. 199: 291-297

Yen, A., Williams, M., Platko, J. D., Der, C. and Hisaka, M. (1994) Expression of activated RAF accelerates cell differentiation and RB protein down-regulation but not hypophosphorylation. Eur. J. Cell Biol. 65: 103-113

Yoon, J. W., Kim, D. J., Chung, Y. C., Park, J. K. and Kim, T. J. (1993) Color removal of culture broth containing hyaluronic acid by activated carbon. Kor. J. Biotechnol. Bioeng. 8: $143-149$ 